Esta revista forma parte del acervo de la Biblioteca Jurídica Virtual del Instituto de Investigaciones Jurídicas de la UNAM

\title{
Reflexiones filosóficas sobre la antropología del derecho*
}

\section{Philosophical Reflections on Legal Anthropology}

\author{
Guillermo José MAÑón GARIBAY**
}

\section{Resumen:}

En los últimos años se ha visto aumentar significativamente los resultados de las ciencias neurocognitivas y el estudio de los diferentes mecanismos que actúan sobre la conciencia, sobre la identidad personal, sobre el comportamiento libre, sobre la conciencia de culpa o arrepentimiento. Este trabajo analiza la conducta normativa del hombre desde el punto de vista antropológico, derivado de los recientes avances biológicos, médicos, bioquímicos y psicológicos. Dicha perspectiva representa, sin lugar a dudas, un logro en el estudio inter, multi y transdisciplinario del hombre y su conducta, en específico de aquella organizada por reglas. El artículo sugiere que responder a la pregunta sobre la relevancia de las propiedades básicas del cerebro, su actividad electroquímica, su plasticidad sináptica o el tipo de neurotransmisión, para el derecho no puede provenir sino de la filosofía.

\section{Palabras clave:}

Antropología del derecho, comportamiento normativo, biología y derecho, neurociencia.

* Artículo recibido el 16 de octubre de 2015 y aceptado para su publicación el 23 de marzo de 2016.

** Investigador de tiempo completo definitivo por oposición en el Instituto de Investigaciones Jurídicas de la Universidad Nacional Autónoma de México. 
Esta revista forma parte del acervo de la Biblioteca Jurídica Virtual del Instituto de Investigaciones Jurídicas de la UNAM

GUILLERMO JOSÉ MAÑÓN GARIBAY

\section{Abstract:}

Results stemming from neurocognitive science and the analysis of several mechanisms that alter consciousness, personal identity, free will, sense of guilt or regret have shown a notable growth in recent years. This work addresses the normative behavior from an anthropological view, considering the latest biological, medical, biochemical and psychological progresses reached. Such a view undoubtedly portrays an achievement for interdisciplinary, multidisciplinary and trans disciplinary studies on man and his behavior, particular$l y$, the rule-oriented one. This paper suggests that the answer to the question about relevance of the brain's basic properties, its electrochemical activity, synaptic plasticity or the type of neurotransmission, in law cannot but come from philosophy.

\section{Keywords:}

Anthropology of law, normative behavior, biology and law, neuroscience. 
Esta revista forma parte del acervo de la Biblioteca Jurídica Virtual del Instituto de Investigaciones Jurídicas de la UNAM

SumARIo: I. Introducción. II. ¿Qué es la antropología del derecho? III. Cultura y biología. IV. Filosofía de la antropología. V. La filosofía y teoría de la evolución frente a sus detractores. VI. La idea del hombre en la biología y en el derecho. VII. Conclusiones. VIII. Bibliografía.

\section{INTRODUCCIÓN}

¿Puede una ética normativa, orientada a la consecución del mayor bien, aclarar sus normas desde la teoría evolutiva? ${ }^{1}$ Sabemos que la naturaleza toda - incluyendo la humana- no sirve de paradigma o ideal normativo. Lo que es natural no es ni bueno ni justo o - como comúnmente se ha formulado- de un simple "es" no se deriva un "debe ser". 2

Entonces, la pertinencia del análisis evolutivo sobre el origen del hombre y su cultura no puede tener una finalidad normativa. Sin embargo, la pregunta: ¿qué debe ser el hombre?, presupone la respuesta a otra previa: ¿qué es el hombre? Y la respuesta sólo puede provenir de las ciencias naturales y no de la especulación sobre una esencia humana oculta a la experimentación.

El comportamiento normativo precisa de imperativos categóricos con garantías elementales sobre su cumplimiento real, fuera de la ilusión desbordada o ingenua; por ello, atendiendo a esta consideración, caen por su propio peso los reparos contra la herencia darwininana.

\section{II. ¿QUÉ ES LA ANTROPOLOGÍA DEL DERECHO?}

La antropología del derecho analiza el comportamiento normativo del hombre desde el punto de vista de las disposiciones evolutivas. ${ }^{3}$ Esto implica dos cosas: primero, que pueden ser explicados algunos

1 Piepper, Annemarie, Einführung in die Ethik, München,UTB Verlag, 2000, pp. 251-255.

2 Foot, Philippa, Las virtudes y los vicios, México, UNAM, 1994, p. 93.

3 Ehrencron, Phillipp, Antropologie des Rechts, München, GRIN Verlag, 2008, p. 65. 
Esta revista forma parte del acervo de la Biblioteca Jurídica Virtual del Instituto de Investigaciones Jurídicas de la UNAM

ámbitos del derecho desde las ciencias naturales (principalmente la biología y la neurología), y, segundo, que el comportamiento normativo del hombre es el resultado del intercambio entre genes y cultura. Lo que significa que los patrones básicos de comportamiento normativo humano tienen como condición necesaria las disposiciones naturales dadas en la información genética, y que las reflexiones sobre el derecho son también el resultado del diálogo entre las disposiciones genéticas y culturales.

En el centro de este análisis filosófico-antropológico del derecho se encuentran, además de conceptos como persona, (auto)conciencia, voluntad libre y responsabilidad, propios de todo análisis de la conducta normativa, los conceptos de estrategias mixtas de comportamiento ${ }^{4}$ (útil para explicar la transformación de la norma consuetudinaria en derecho positivo) y condiciones contextuales óptimas ${ }^{5}$ (útil para explicar la obediencia o desacato a las normas sociales).

La pregunta sobre los servicios que brinda la conducta normativa en nuestro mundo, amenazado por los intereses de grupo y la violencia, se formula así: ¿qué tan universales son los derechos humanos en un mundo de economía y tecnología globalizada en el que persisten las tensiones entre derechos e intereses? ¿Cómo puede tener lugar bajo estas condiciones un respeto a los derechos humanos?

Por un lado, es verdad que un moralismo normativo no garantiza el cumplimiento de los derechos humanos, ya que éstos sólo pueden ser practicados bajo el auspicio del Estado: derechos humanos son en la práctica derechos ciudadanos. Por otro lado, la normatividad del comportamiento práctico no puede ser delegada a la ciencia (económica) o al desarrollo tecnológico; incluso pueden fracasar ambas cuando se le adjudica el papel de autoridad normativa, simplemente porque en la ciencia (y tecnología) se trata de la verdad y eficacia y no de la justicia social. Por el contrario, ciencia y tecnología precisan de una normatividad ética-jurídica como su asociado. Las dos grandes guerras del siglo XX, y todos los conflictos actuales,

4 Mohr, Hans, Evolutionäre Ethik, Wiesbaden, Springer Spektrum, 2014, pp. 15 y ss.

5 Idem. 
Esta revista forma parte del acervo de la Biblioteca Jurídica Virtual del Instituto de Investigaciones Jurídicas de la UNAM

han puesto de manifiesto el atraso de la ética y el derecho respecto del avance de la técnica y el uso de la investigación científica con fines bélicos.

Frente a esto, Friedrich von Hayek ${ }^{6}$ avizoró la solución en el punto de vista evolutivo, pero con consecuencias inadmisibles. Él y sus colegas de Freiburg expresaron su desconfianza por el constructivismo, ${ }^{7}$ o sea, por aquella concepción originada en la Ilustración que afirmaba la posibilidad de un nuevo orden apoyado únicamente en la planeación racional científica. Como reacción, Hayek propuso el orden espontáneo de la evolución, según el cual las instituciones de la sociedad (morales y jurídicas) no fueran un invento o diseño racional humano, sino fruto de un orden espontáneo, resultado de la acción humana, pero sin un diseño racional estricto.

El concepto de orden espontáneo alude a la formación de sistemas desarrollados sin planeación alguna o impulsados por el beneficio personal. Ese es el caso — según Hayek — de la evolución de la vida sobre la Tierra, del lenguaje humano, del derecho, la economía de mercado y el sistema de precios, etcétera.

Hoy día no se puede seguir la visión de Hayek sobre una evolución cultural que se ordene por sí sola; antes bien, hay que apostar por un desarrollo cultural guiado por la razón. En la situación actual del mundo, no nos podemos dar el lujo de confiar en el ensayo y error o estar a la espera de que un "orden espontáneo" caiga del cielo. Un comportamiento normativo que busca dirigir la evolución cultural de manera racional y humana tiene que tomar en cuenta factores como nuestra innata inclinación natural, los problemas mundiales actuales y la transformación racional de la cultura para solucionarlos. Entonces, el mundo depende de lo que nosotros hagamos racionalmente, y el homo sapiens no puede sobrevivir sin redoblar sus esfuerzos en este aspecto, porque estamos en un momento de la evolución cultural que exige sentar nuevas pautas para el pensa-

${ }^{6}$ Hayek, Friedrich August, von, Evolution, Wissen und spontane Ordnung. Die Anmassung von Wissen. Teil I, Tübingen, Mohr Verlag, 1996. Y, Individualismus und wirtschaftliche Ordnung, Wien, Rentsch Verlag, 1952.

7 Como es el caso de la epistemología social de Ernst von Glasersfeld. Véase Glasersfeld, Ernst von, Radikaler Konstruktivismus: Ideen, Ergebnisse, Probleme, Frankfurt, Suhrkamp Verlag, 1997. 
Esta revista forma parte del acervo de la Biblioteca Jurídica Virtual del Instituto de Investigaciones Jurídicas de la UNAM

miento jurídico y bioético. Por ello, la mirada inteligente de los legisladores deberá reconocer siempre la línea divisoria entre lo dado y lo adquirido, lo natural y lo cultural, así como las aptitudes inclusivas y las propiedades emergentes, acreditadas a lo largo de la evolución y necesarias para entender el comportamiento normativo humano.

\section{Cultura y BIOLOGÍA}

En un principio, las ciencias de la cultura (antropología, sociología, psicología filosofía de la cultura) se enfrentaron a la teoría evolucionista: el llamado modelo cultural de las ciencias sociales ${ }^{8}$ enfatizó la influencia del medio ambiente (cultural), mientras que los evolucionistas lo hicieron respecto a la información genética y sus transformaciones evolutivas.

Tomando un rasgo humano cualquiera (i. e., sociabilidad y proclividad al bien, dimorfismo sexual/cerebral y predominancia masculina, reproducción sexual y sexualidad heterosexual, etcétera) se erigieron dos puntos de vista distintos que pretendían explicarlo y/o justificarlo: uno, desde el medioambiente cultural; otro, desde la estructura genética. Si bien ambos puntos de vista no eran y no son excluyentes, el debate residía en determinar la relevancia de uno y otro ámbito; por ejemplo: algunos filósofos negaron que los hombres estén en guerra unos con otros y sean codiciosos por naturaleza, ${ }^{9}$ sino que la estructura social los pervierte y convierte en seres egoístas. ${ }^{10}$

8 Harris, Marvin, Introducción a la antropología general, Madrid, Editorial Alianza, 2002, 863 p. Allí, el autor se refiere a la diferencia entre dos tipos de enfoque culturales; uno llamado emic y otro etic. Esta distinción entre emic y etic se usa en las ciencias sociales para discriminar entre la interpretación nativa y la extrajera, respectivamente. Los primeros (emic) están involucrados en los procesos culturales de la comunidad, y los segundos observan desde fuera (etic). Ambos términos fueron creados por el lingüista Kenneth Pike, con base en las palabras phonemics (fonología) y phonetics (fonética), y el antropólogo M. Harris los introdujo a los estudios sociales.

9 Como haría pensar una interpretación del Leviatán de Thomas Hobbes.

10 Como lo explica Rousseau en su ensayo de juventud Discurso sobre el origen y fundamento de la desigualdad entre los hombres (Buenos Aires, Editorial Leviatan, 2004, 127 pp.). 
Esta revista forma parte del acervo de la Biblioteca Jurídica Virtual del Instituto de Investigaciones Jurídicas de la UNAM

Del mismo modo, las feministas afirmaron que la causa del dominio masculino en la sociedad no surgió del dimorfismo sexual/cerebral natural, sino de la cultura patriarcal. Por último, los movimientos a favor de los derechos homosexuales han puesto en tela de juicio la sexualidad reproductiva heterosexual como única posible, y responsabilizaron a los prejuicios sociales de la exclusión de cualquier otra forma de sexualidad que aquella que conduce a la reproducción. Los tres puntos de vista anteponen los factores culturales a los biológicos evolutivos, hasta el punto de rechazar plenamente el aspecto biológico. Por ello, el llamado modelo cultural de las ciencias sociales se niega a admitir la existencia de la naturaleza humana, sea entendida como esencia metafísica o biológica, pero siempre como un determinante de la conducta del hombre.

Es innegable que la noción de naturaleza humana evoca espontáneamente la idea de algo esencial, fijo y permanente, que determina el ser del hombre ontológica y axiológicamente, tanto a ser un hic et hoc como a guiarse por un ideal normativo. Actualmente, el concepto de naturaleza humana tiene un significado puramente descriptivo, establecido a partir de principios estadísticos sobre la conducta de las poblaciones, y cuya validez varía al ritmo de las distintas etapas de su desarrollo histórico.

La biología evolucionista acepta que el hombre constituye una especie per se, pero, a la vez que subraya su especificidad genética, afirma su evolución permanente. Nada más alejado de una postura evolucionista que el esencialismo filosófico o el mecanicismo científico. Sin embargo, no se niega el peligro de decretar desde el evolucionismo un determinismo biológico, porque si bien una cosa es decir que la información genética influye en la conducta del hombre, otra muy distinta es afirmar que la determina, y no es fácil reconocer el límite y diferencia de lo primero y lo segundo. Aparte del reduccionismo, no se olvida que el darwinismo social inspiró movimientos políticos como el nazismo y fascismo o el racismo y el sexismo, y sigue siendo sin lugar a dudas el fantasma que recorre el mundo cultural. Hoy día, ser políticamente correcto significa rechazar el darwinismo social y los intentos deterministas de la biología evolutiva, lo que puede llevar a considerar puramente el aspecto sociocultural como relevante. 
Esta revista forma parte del acervo de la Biblioteca Jurídica Virtual del Instituto de Investigaciones Jurídicas de la UNAM

Para no caer en uno u otro extremo, es necesario dirimir hasta qué punto el evolucionismo puede extenderse más allá de los límites de la biología o, de otra manera, saber si la biología evolutiva es capaz de proporcionar un conocimiento de la naturaleza cultural del hombre. Por ello, la pregunta se formula así: ¿hasta qué punto el enfoque evolutivo ayuda a entender conceptos como (auto-)conciencia, voluntad libre y responsabilidad, etcétera?

Ya se dijo que la antropología filosófica del derecho ofrece conceptos como el de estrategias mixtas de comportamiento ${ }^{11}$ y condiciones contextuales óptimas. ${ }^{12}$ La cuestión es sobre su relevancia explicativa frente a la tarea tradicional de la filosofía, a saber: ponderar y justificar lo que es correcto desde la perspectiva de un sistema valorativo dado. La reflexión filosófica se ha entendido como una teoría de lo correcto, de lo justo y de lo bueno, ${ }^{13}$ y la antropología del derecho reflexiona sobre el ethos (i. e., las acciones, costumbres y hábitos normativos) desde un punto de vista descriptivo. El ethos representa para el antropólogo la práctica cotidiana de un sistema de valores que constituye el hilo conductor del comportamiento y conciencia normativa, sin importar si las normas se cumplen o transgreden o si se les formula implícita o explícitamente o si el ethos social es susceptible de sistematizarse a partir de una estructura jerárquica de valores finales (últimos) y valores instrumentales o mediadores. ${ }^{14}$

\section{Filosofía DE LA ANTROPOLOGÍA}

Tanto en el caso del enfoque filosófico tradicional como en el antropológico es posible extender la reflexión ascendiendo a un metanivel, para dar cuenta de la estructura lógica de los juicios normativos y para explicar la génesis de estos juicios. En este segundo

11 Mohr, Hans, Evolutionäre Ethik, Wiesbaden, Springer Spektrum, 2014, pp. 15 y ss.

12 Idem.

13 Röd, Wolfgang, Keline Geschichte der antike Philosophie, München, C. H. Beck Verlag, 1998, pp. 172 y ss.

14 Lampe, Ernst-Joachim, Rechtsantropologie, Berlín, Dunker \& Humblot Verlag, 1970, pp. 17 y ss. 
Esta revista forma parte del acervo de la Biblioteca Jurídica Virtual del Instituto de Investigaciones Jurídicas de la UNAM

metanivel, el análisis del comportamiento humano se concentra en sus disposiciones evolutivas, permitiendo el estudio del comportamiento normativo desde las ciencias naturales. Por ello, en este contexto se asume la validez de la teoría biológico-evolutiva darwiniana, así como de su extenso contexto naturalista. ${ }^{15}$

El concepto de evolución (exactamente evolución biológica) incluye dos aspectos: el desarrollo histórico de los seres vivos dentro de la evolución geológica entera y la creatividad del proceso que forja siempre algo nuevo, incrementando la complejidad de los organismos hasta crear el sistema más complejo conocido hasta ahora: el cerebro humano.

\section{LA FILOSOFÍA Y TEORÍA DE LA EVOLUCIÓN FRENTE A SUS DETRACTORES}

La evolución es un hecho comprobado científicamente, del cual ningún especialista puede dudar seriamente, y con el cual se está en condiciones de reconstruir el proceso evolutivo de la Tierra en su conjunto. Desde el siglo XIX, la biología evolutiva explica científicamente el hecho incontrovertible de la evolución. La pregunta actual dice: ¿qué tan digna de confianza es la teoría evolutiva del presente siglo, que no sólo se basa en las observaciones y conclusiones de la biología comparada, en las investigaciones paleontológicas y biogeográficas, como en su tiempo la teoría de Darwin, sino además, en los avances científicos de la genética, de la biología molecular, de la genómica y de la biología sistemática? La pregunta es pertinente, porque la teoría moderna de la evolución constituye el paradigma explicativo de toda la biología actual, ${ }^{16}$ y la respuesta ofrece una enorme cantidad de evidencias en todos los ámbitos de la biología, así como la ausencia de un caso contrafactual importante. Además, la teoría de la evolución aclara la capacidad adaptativa de los orga-

15 Hartmann, Dirk, "Posttraditionalität und Ethik", en Janich, Peter (ed.), Naturalismus und Menschenbild, Meiner Verlag, Hamburg 2008, pp. 67-126.

16 Wuketits, Franz, Darwin und der Darwinismus, München, C. H. Beck Verlag, 2005, pp. 87-93. 
Esta revista forma parte del acervo de la Biblioteca Jurídica Virtual del Instituto de Investigaciones Jurídicas de la UNAM

nismos, de sus insuficiencias, sus disfunciones y muerte. También permite explicar la existencia de fósiles vivientes y el hecho de que la mayoría de las líneas evolutivas respecto al mismo hayan desaparecido. Éstas son algunas razones para aceptar la teoría evolutiva como paradigma explicativo de la biología y para afirmar que no hay alternativa frente a ella. ${ }^{17}$

No obstante, hay reacciones en contra que objetan a la teoría evolutiva el ser una teoría puramente naturalista y no teísta. Lo que significa que en la teoría evolutiva no se reconoce el papel explicativo de las fuerzas sobrenaturales. Los críticos resienten, por ejemplo, la falta de reconocimiento a las narraciones sobre la creación plasmadas en el Génesis. En respuesta, los evolucionistas consideran que los mitos bíblicos sobre la creación, pese a su lenguaje y belleza, no tienen conexión con la realidad del mundo, como sí lo tienen las teorías sobre la evolución de las especies, la hominización y origen del homo sapiens. Adoptar una postura intermedia entre teístas y naturalistas, a la manera de Spinoza, Kant y Einstein, quienes abandonaron al Dios de la teología y se afiliaron al Dios de la religión natural, ${ }^{18}$ no soluciona el problema: la diferencia entre teísmo y naturalismo no es de grado, sino de principios.

Recientemente el creacionismo ha resurgido en nuestros tiempos bajo el eufemismo de "teoría del diseño inteligente", pretendiendo ser una opción frente a la teoría de la evolución. Sin embargo, no se trata de una verdadera teoría científica, sino de un pensamiento mágico con vestimenta de laboratorio. Un ejemplo de esto es la homilía de Benedicto XVI:

Creemos en Dios. Esta es nuestra opción fundamental. Pero, nos preguntamos de nuevo: ¿es posible esto aún hoy? ¿Es algo razonable? Desde la Ilustración, al menos una parte de la ciencia se dedica con empeño a buscar una explicación del mundo en la que Dios sería superfluo. Y si eso

17 Engels, Eve-Marie, \& Darwin, Charles, "Person, Theorie, Rezeption”, en Engels, Eve-Marie (editora), Charles Darwin und seine Wirkung, Frankfurt am Main, Suhrkamp Verlag, 2009, pp. 9-58.

18 Weischedel, Wilhelm, Der Gott der Philosophen, Darmstadt, Wissenschaftliche Buchgesellschaft, 1995. 
Esta revista forma parte del acervo de la Biblioteca Jurídica Virtual del Instituto de Investigaciones Jurídicas de la UNAM

fuera así, Dios sería inútil también para nuestra vida. Pero cada vez que parecía que este intento había tenido éxito, inevitablemente resultaba evidente que las cuentas no cuadran. Las cuentas sobre el hombre, sin Dios, no cuadran; y las cuentas sobre el mundo, sobre todo el universo, sin él no cuadran. En resumidas cuentas, quedan dos alternativas: ¿Qué hay en el origen? La Razón creadora, el Espíritu creador que obra todo y suscita el desarrollo, o la Irracionalidad que, carente de toda razón, produce extrañamente un cosmos ordenado de modo matemático, así como el hombre y su razón. Esta, sin embargo, no sería más que un resultado casual de la evolución y, por tanto, en el fondo, también algo irracional. ${ }^{19}$

Ciertamente, la cuestión fundamental que plantea una religión revelada permanece sin respuesta dentro de una teoría naturalista, a saber: el problema sobre el comienzo del mundo. Sin embargo, no más cierto es que los teólogos fracasan frente a la pregunta sobre por qué hay un creador y por qué creó las leyes naturales como las conocemos. ${ }^{20}$ Desde la perspectiva teísta, la teoría naturalista de la evolución es limitada, por dejar fuera las fuerzas sobrenaturales, y desde la perspectiva naturalista, la teología es limitada, por dejar fuera la experimentación.

Como ciencia experimental, la biología evolutiva se presenta como un enfoque descriptivo y no normativo. Las razones por las cuales una teoría evolutiva, enfocada a explicar la conducta normativa del hombre, debe renunciar a las aspiraciones de una disciplina normativa, residen, entre otras cosas, en que las ventajas de la evolución

19 Benedicto XVI, Sermón pronunciado en la explanada de Isling, Ratisbona, septiembre de 2006.

20 En este tenor, Wittgenstein propone en su conferencia sobre ética (del 17 de noviembre de 1929, publicada en 1965) la diferencia entre problemas con sentido y sinsentido: "Carece de sentido decir que me asombro de la existencia del mundo, porque no puedo representármelo no siendo. Naturalmente, podría asombrarme de que el mundo que me rodea sea como es. Si mientras miro el cielo azul yo tuviera esta experiencia, podría asombrarme de que el cielo sea azul, en vez de que esté nublado. Pero no es a esto a lo que ahora me refiero. Me asombro del hecho de que haya cielo, sea cual sea su apariencia". Para Wittgenstein, los problemas de la teología no tendrían sentido. Wittgenstein, Ludwig, Lecture on Ethics, Wiley Blackwell, University College, 2014, pp. 8 y ss. 
Esta revista forma parte del acervo de la Biblioteca Jurídica Virtual del Instituto de Investigaciones Jurídicas de la UNAM

biológica no garantizan el éxito de los valores normativos creados por la cultural. ${ }^{21}$ Por ello, los avances evolutivos de la conducta normativa deben ser referidos al progreso cultural, y no genético. Sin embargo, no es baladí para todo estudioso de la esfera normativa informarse sobre las investigaciones de la evolución biológica, y, en especial, sobre los estudios de la evolución de la conducta normativa del hombre. La razón de esto es que si se observa la desproporción entre nuestra herencia biológica y cultural, se constatará que la herencia biológica es con mucho el factor constante, cuyos detalles son bastante bien conocidos, así como su influjo sobre el hombre y la cultura moderna. También porque, pese al reconocimiento de la plasticidad que caracteriza al homo sapiens, se deben aceptar y respetar las fronteras que su genoma le impone. Esto no anula la condición para la supervivencia humana, a saber: el que los hombres estén y hayan estado compelidos al desarrollo de sus capaci-dades culturales para su convivencia y armonía con el entorno. ${ }^{22}$

La reflexión filosófica sobre la antropología del derecho deberá someter a prueba la pertinencia de la evolución para el análisis de la conducta normativa del hombre, así como la racionalidad de los juicios normativos frente a la necesidad de su socialización. No se trata de aportar la última justificación de los enunciados normativos ni su consistencia y coherencia lógica, sino de mostrar la pertinencia del análisis evolutivo para su comprensión. ${ }^{23}$

\section{LA IDEA DEL HOMBRE EN LA BIOLOGÍA Y EN EL DERECHO}

La evolución genética y cultural constituye la naturaleza escindida del hombre, debatiéndose entre inclinaciones y obligaciones, ofreciendo condiciones favorables para el comportamiento normativo y el desarrollo de una mejor convivencia social. La evolución del comportamiento normativo del hombre supuso la adjudicación de res-

21 De Waal, Frans, Der gute Affe, München, Hanser Verlag, 1997, pp. 16-32.

22 Hermanni, Friedrich, "Naturalisierung der Ehtik", en Wetz-Steenblock (ed.), Praktiche Philosophie, Reclam, Stuttgart, 2008, pp. 65-96.

${ }_{23}$ Markl, Hubert, Homo sapiens, Münster, Rhema Verlag, 1998, pp. 5 y ss. 
Esta revista forma parte del acervo de la Biblioteca Jurídica Virtual del Instituto de Investigaciones Jurídicas de la UNAM

ponsabilidad, lo que a su vez supuso, como condición de posibilidad, la conciencia de uno mismo (autoconciencia) y la voluntad libre. ${ }^{24}$ Para entender el yo y la voluntad libre, todo científico (biólogo o neurofisiólogo) parte del hecho de que para cada acto consciente del yo hay un suceso neuropsicológico correspondiente (exactamente una función del sistema nervioso central, en especial del cerebro).$^{25}$ Esta referencia a las neurociencias está basada en muchos experimentos y observaciones controladas que muestran el vínculo entre cerebro y eventos mentales, y permite a los especialistas desarrollar terapias bioquímicas para esquizofrénicos y establecer la urdimbre hereditaria de las enfermedades mentales. Desde el punto de vista evolutivo, se reconocen las ventajas que ha ofrecido para la supervivencia del hombre su elaborado sistema nervioso central y la posesión de una conciencia subjetiva, ${ }^{26}$ pese a su vulnerabilidad; porque la simple experiencia del sentido común sabe de las nocivas consecuencias que tiene el alcohol o la nicotina o los psicofármacos o las endorfinas sobre la conciencia y su percepción del mundo.

La explicación evolutiva de esta conciencia ha permitido también a la cultura ecológica moderna la oportunidad de crear una nueva actitud hacia los animales, impregnada de espíritu cartesiano hasta hace poco, gracias al progreso de la neurociencia y su conocimiento sobre los procesos cognitivos; porque si se acepta que la conciencia se formó gradualmente a lo largo de la evolución, entonces se deberá adjudicar (en algún grado) a los animales tanto conciencia de sí como pensamiento teleológico, y así justificar un trato considerado hacia ellos.

Por todo lo anterior, se asume que la conciencia del yo es un correlato muy complejo del sistema nervioso central, que obliga a reconocer que no hay claridad absoluta sobre la relación cerebro/conciencia o si el número de neuronas y el grado de conexión entre ellas

24 Piepper, Annemarie, Einführung in die Ethik, München, UTB Verlag, 2000, pp. 164-171, y Williams, Bernard, Problemas del Yo, México, UNAM, 1986, pp. 219-245 y 271-301.

25 Lazorthes, Guy, El cerebro y la mente, México, Conacyt-Ediciones Castell Mexicana, 1987, pp. 97-125.

26 Changeux, Jean-Pierre, El hombre de verdad, México, Fondo de Cultura Económica, 2005 pp. 79-114, 
Esta revista forma parte del acervo de la Biblioteca Jurídica Virtual del Instituto de Investigaciones Jurídicas de la UNAM

describe suficientemente la aparición y organización de cada uno de los eventos mentales. ${ }^{27}$

Pese al avance de la ciencia, perdura el problema mente-cuerpo. Los neurobiólogos evolutivos no dudan de la naturaleza biológica del hombre, y por ello lo explican con la teoría evolutiva sin reserva alguna. Al mismo tiempo reconocen con Kant que la fe en la ley moral y en la autonomía de la voluntad libre es una condición necesaria del comportamiento normativo. ¿Cómo es posible relacionar causal y armoniosamente las determinaciones corporales con la concepción de una conciencia libre y autónoma? No hay una respuesta satis-factoria para este antiguo dilema: los dualistas no pueden explicar cómo el espíritu inmaterial y sin energía influye causalmente en el cerebro (no hay causalidad sin transmisión de energía). En tanto que los monistas no pueden aclarar la autoconciencia y la libertad. ${ }^{28}$ El problema mente-cuerpo permanece una aporía, un problema insoluble, frente al cual la antropología evolutiva propone al yo (a la conciencia yoica) como una propiedad emergente, o sea, una propiedad que surge dentro del funcionamiento de un sistema colaborativo, pero sin reducirse a ninguna pieza del mismo.

Si bien desde el punto de vista funcional esto ofrece una solución, hay que reconocer que el problema mente-cuerpo muestra la frontera de la capacidad humana de conocimiento. Se está en condiciones de formular la aporía, pero no de solucionarla. El cerebro más evolucionado de la naturaleza fracasa en la reflexión sobre sí mismo, en la explicación de la relación entre el microcosmos mental y el macrocosmos biológico. La comunicación entre mundo material y mundo espiritual, con su demanda de libertad, no puede ser suficientemente explicada, y por ello hay que aceptar la dimensión ininteligibles de esta realidad. Lo que no desmiente la verdad sobre que la hominización y evolución del hombre ha abierto nuevas dimensiones argumentativas que no existían para el naturalismo de los siglos XVIII y XIX. ${ }^{29}$

27 Idem.

28 Campbell, Keith, Cuerpo y mente, México, UNAM, 1987, pp. 41-53 y 73-96.

${ }^{29}$ Janich, Peter, "Naturwissenschaft vom Menschen versus Philosophie", en Janich, Peter (ed.), Naturalismus und Menschenbild, Hamburg, Meiner Verlag, 2008, pp. 30-52. 
Esta revista forma parte del acervo de la Biblioteca Jurídica Virtual del Instituto de Investigaciones Jurídicas de la UNAM

La responsabilidad moral y jurídica permanecerá oscura mientras se proponga como solución la hipostasis del yo y su voluntad libre. ${ }^{30}$ La antropología filosófica evolutiva avanza al explicar la libertad del yo dentro de la evolución del hombre como una propiedad emergente, necesaria para el éxito de la hominización. ${ }^{31}$ Aquí es nuevamente relevante mencionar que "entidades ficticias" tienen un lugar relevante a lo largo de la evolución, igual que los factores reales. Esta propuesta antropológica sortea la dificultad de la relación mente-cuerpo al asumir un yo y su voluntad libre dentro de la razón práctica, pero aclarando que ambos solamente se entienden como propiedades emergentes de la socialización.

Concisamente, puede decirse que la vida cultural del hombre moderno precisa de la presunción de la libertad y de la responsabilidad del yo. La concepción clásica del naturalismo no ofreció ninguna explicación para esta asunción, y hoy día, como consecuencia de la teoría cuántica, han tenido lugar especulaciones aventuradas que nos devuelve al escepticismo de antaño: el físico alemán Thomas Görnitz ${ }^{32}$ creyó explicar al yo y su libertad con la teoría cuántica y propuso a los pensamientos como entidades tan reales como los átomos. Con ello, Görnitz pensó haber eliminado la separación cartesiana entre sustancia pensante y sustancia extensa, y tomar el yo y la voluntad libre como entes "reales". Sin embargo, las explicaciones de Görnitz no aciertan siquiera a formular correctamente el problema. Sus disquisiciones se suman a los múltiples intentos fallidos frente al problema mente-cuerpo, y la pregunta persiste: ¿cómo es sostenible nuestra concepción del mundo natural con el planteamiento sobre nuestra voluntad libre?

Contrariamente a la visión de Görnitz, el teólogo católico Karl Rahner ${ }^{33}$ prefirió imaginar a la materia como "espíritu congelado",

30 Williams, Bernard, Problemas del yo, México, UNAM, 1986, pp. 219-245 y 271301.

31 Mohr, Hans, Evolutionäre Ethik, Heidelberg, Springer Spektrum, Heidelberg Akademie der Wissenschaft, 2014, pp. 35-38.

32 Görnitz, Thomas y Görnitz, Brigitte, Der Kreative Kosmos: Geist und Materie aus Information, Heidelberg, Spektrum akademischer Verlag, 2002.

33 Rahner, Karl, Das Problem der Hominisation, Über den biologischen Ursprung des Menschen, Wien, Herder Verlag, 1965, p. 319. 
Esta revista forma parte del acervo de la Biblioteca Jurídica Virtual del Instituto de Investigaciones Jurídicas de la UNAM

pero ¿es compatible esta afirmación con nuestra concepción del mundo natural? Porque nadie está en condiciones de negar la naturaleza escindida del hombre producto de la evolución y debatiéndose entre genes y cultura. Y aunque no haya una solución definitiva para el problema mente-cuerpo, sí existe la posibilidad, a través de la evolución cerebral, de crear condiciones óptimas para nuestra herencia cultural: crear un contexto cultural apropiado para la mejor manifestación de los altos valores sociales.

La pregunta es si la moral y el derecho ofrecen una garantía sobre nuestra evolución cultural y si continuarán en la dirección a un mundo mejor. Por un lado, se piensa que una moral no es suficiente y que el derecho debe ser el que garantice el orden y la evolución de la cultura; por otro lado, se propone como solución una ética mundial o una moral global (Weltethos), en el sentido de Hans Küng. ${ }^{34}$ Los primeros llegan a esta conclusión por la insuficiencia de la moral ante el advenimiento del derecho positivo como palanca del desarrollo cultural: según ellos, la moral funciona únicamente cuando hay poca complejidad en el sistema social y bajo una secuencia simple de causa-efecto-sanción. ${ }^{35}$ El prototipo de esto es la moral dinástica del Antiguo Testamento, susceptible de ser resumida en diez mandamientos (decálogo). El libro del Génesis describe el mundo antes del derecho, ${ }^{36}$ mostrando una mezcla incongruente de injusticias y barbarie frente al celo iracundo de un Dios ordenador. Sus amonestaciones morales fueron perdiendo efectividad con la creciente complejidad y gravedad de los problemas sociales. Por eso - se dice - aparece el derecho al lado de la moral y desplazando a la moral. Ahora, el ámbito de regulación del derecho es el ámbito de las instituciones, del Estado constitucional y su administración gubernamental producto de un contrato social, paradigma de convivencia pacífica, garantía de resolución de conflictos por un Poder 1999.

34 Küng, Hans, Una ética mundial para la política y economía, Madrid, Trotta,

35 Kunz, Karl-Ludwig, y Mona, Martino, Rechtsphilosophie, Rechtstheorie, Rechtssoziologie, Stuttgart, UTB Verlag, 2006, p. 31.

${ }^{36}$ Brunkhorst, Hauke, Einführung in die Geschichte politischer Ideen, Köln, UTB, 2006, p. 88. 
Esta revista forma parte del acervo de la Biblioteca Jurídica Virtual del Instituto de Investigaciones Jurídicas de la UNAM

Judicial imparcial. La idea jurídica de justicia recibe, de esta manera, un lugar preponderante, acorde al tamaño y complejidad de las sociedades actuales.

Sin embargo, el derecho positivo trae consigo ventajas y desventajas; por un lado, las sentencias normativas poseen fuerza jurídica, $\mathrm{y}$, por otro, el acto positivo de promulgar leyes permite cuestionar la legitimidad del legislador. Nadie puede negar la posibilidad de un sistema jurídico injusto, y con ello, admitir, tácita o explícitamente, la posibilidad de revisar el valor del derecho mediante principios éticos o metajurídicos. Respecto a este punto, parece reivindicarse la necesidad de principios morales universales. Ciertamente, las cuestiones sobre la legitimidad del legislador y sus leyes se resuelven en la sociedad democrática de manera distinta a aquella aportada en las narraciones bíblicas o el Estado absolutista. Si entendemos un orden jurídico como un logro evolutivo que implica legislar con creatividad, con normas jurídicas racionales y una jurisprudencia establecida, además de un juez imparcial sancionando según la ley y gravedad de la violación, entonces, su posible cuestionamiento solamente puede dimanar a través de principios morales universales y metajurídicos.

Lo que no niega que el invento del derecho positivo haya sido una condición sine qua non de la evolución cultural. El avance en la convivencia humana va de la mano de la construcción del Estado de derecho y sus leyes desvinculadas de las veleidades divinas o arbitrariedades absolutistas. Desde la antigua polis griega se hacen intentos para superar la moral religiosa: Sócrates, ${ }^{37}$ en el Critón, rechazaba las normas fuera del derecho y, consecuentemente, justificó la obediencia al derecho excluyendo las creencias y autoridades religiosas o extrajurídicas. Por ello, Sócrates se niega a huir de Atenas y evadir la ejecución de la sentencia, pese a su injusticia.

Desde entonces, derecho y moral parecen ser rivales en la historia del pensamiento; desde entonces, las controversias entre puntos de vista jurídicos y morales son el pan de todos los días. Este conflicto normativo ha dado lugar a problemas como el de objeción de conciencia y desobediencia civil, ${ }^{38}$ a casos planteados por los vacíos

37 Höffe, Otfried, Gerechtichkeit, München, C. H. Beck Verlag, p. 53.

38 Laker, Thomas, Ziviler Ungehorsam, Badeb-Baden, Nomos Verlagsgesellschaft, 1996, pp. 52-82. 
Esta revista forma parte del acervo de la Biblioteca Jurídica Virtual del Instituto de Investigaciones Jurídicas de la UNAM

de la ley y la pertinencia de llenarlos con las convicciones morales, a conflictos entre moral religiosa y Estado laico, entre normatividad eclesiástica y el respeto a la autonomía de la conciencia, sea por parte del derecho canónico católico o de la sharia musulmana.

Existe el problema lógico de enjuiciar desde la moral aquella parte del derecho positivo que resulta reprobable, porque se puede afirmar que los principios morales y jurídicos son inconmensurables, y es absurdo afirmar que unos comprendan a los otros y se deriven de ellos. Pero si bien el sistema constitucional parece ofrecer no sólo el marco para el funcionamiento de los órganos estatales, sino además el fundamento del orden social entero (incluyendo los valores morales), no se está por esto blindado, por ejemplo, de aquello acaecido durante los tiempos de la Alemania nazi, donde muchos ciudadanos cumplieron con su obligación de acatar la ley, al estilo de Sócrates, porque temieron más a la desaparición del orden estatal que a la arbitrariedad del Estado. Nadie puede negar que el Estado de derecho proyecta y estabiliza el sistema de valores sociales, y que, por ello, su cuestionamiento involucra la realidad social entera. ${ }^{39}$ La realidad del Estado y sus instituciones representa para muchos la expresión de un orden de valores objetivos, sobre todo en su función de fuerza correctiva.

\section{CONCLUSIONES}

El análisis del comportamiento normativo (específicamente del derecho) desde la perspectiva antropológica evolucionista, pone al descubierto principios normativos antiquísimos, provenientes de los tiempos de la evolución de los homínidos. Por esto es posible afirmar que el derecho, en sus axiomas y enunciados positivos, conserva convicciones producto de la evolución biológica: ${ }^{40}$ sea la nece-

39 Kunz, Karl-Ludwig, y Mona, Martino, Rechtsphilosophie, Rechtstheorie, Rechtssoziologie, Stuttgart, UTB Verlag, 2006, p. 109.

${ }^{40}$ Wuketits, Franz, Was ist sociobiologie?, München, Beck Verlag, 2002, pp. 72 y ss. 
Esta revista forma parte del acervo de la Biblioteca Jurídica Virtual del Instituto de Investigaciones Jurídicas de la UNAM

sidad de justicia, honestidad y fraternidad, sea el altruismo mismo; todo se deriva de las aptitudes sociales del homo sapiens.

Además, en el contexto de la teoría de juegos se ha mostrado que hay una inclinación universal hacia la confianza y reciprocidad, y que la regla de oro es una necesidad compartida por todos los hombres. Esto no niega la posible vaguedad de los enunciados metajurídicos o su sujeción a los cambios del tiempo: ${ }^{41}$ bajo justicia social entienden unos ${ }^{42}$ que todos los hombres deben gozar de libertad o de posibilidades para desarrollar todas sus capacidades, etcétera; mientras para otros, ${ }^{43}$ justicia social no tiene mucho que ver con la realización de un proyecto individual de vida y diversas posibilidades de comportamiento, sino más bien con la distribución de la riqueza y el bien colectivo.

El darwinismo moderno, ${ }^{44}$ que opera con el concepto de estrategias mixtas de comportamiento, explica la relevancia social del comportamiento normativo (ético o jurídico) con el concepto de condiciones contextuales óptimas. El principio normativo del bien se lleva a la práctica por la mayoría de los hombres cuando existen condiciones óptimas dentro del contexto social. Así se explica que el "lado oscuro" de la naturaleza humana salga a relucir cuando el contexto de acción social no está dispuesto por la normatividad ética o jurídica, sino por la oportunidad, la ley del más fuerte, el impulso de venganza o el interés personal; o sea, cuando no hay condiciones óptimas de comportamiento social.

Con esta apostilla caen muchas de las objeciones de los detractores del darwinismo. Éstos hacen notar que la evolución de la conciencia y de la conducta normativa del hombre no ha logrado abolir la injusticia, la esclavitud o la pobreza, porque suponen que si la evolución ha sido paralela entre genes y cultura desde que existe el homo sapiens, entonces, se debería estar preparado para la con-

41 Zippelius, Reinhold, Rechtsphilosophie, München, C. H. Beck Verlag, 1994, pp. 200 y ss.

42 Mill, John Stuart, On Liberty, London, Dover Publications, 2003.

43 Marx, Das Kapital, Berlin, Mega, 1978.

44 Beurton, Peter, “Darwins Beitrag zum Genbegrif”, en Engels, Eve-Marie (ed.), Charles Darwin und seine Wirkung, Frankfurt am Main, Suhrkamp Verlag, 2009, pp. 255-276. 
Esta revista forma parte del acervo de la Biblioteca Jurídica Virtual del Instituto de Investigaciones Jurídicas de la UNAM

vivencia como se está para la supervivencia gracias a la evolución genética. Primero, esta objeción asume que los genes condicionan la cultura en un cien por ciento, y que, por tanto, una teoría de la cultura que proponga una explicación análoga a la evolución genética debe ser tajante o concluyente en el intento de entender el cambio cultural y la forma de dirigirnos a un mundo mejor. Sin embargo, se esgrima o no a la evolución para explicar el comportamiento normativo, en ningún caso el derecho o la moral han podido exorcizar del mundo los conflictos de grupo, evitar las guerras o neutralizar el crimen organizado, porque las condiciones óptimas de comportamiento que pueda crear el mejor sistema jurídico no representan de ninguna manera condiciones ideales de comportamiento. Además, es innegable que sin el conocimiento sobre la naturaleza del homo sapiens, aportado por la biología evolutiva, no se hubiera tenido oportunidad de entender y combatir la ambición y abuso de poder con, por ejemplo, la Carta Universal de los Derechos Humanos; porque una de las consecuencias de la evolución genética, y por tanto cultural, es la memoria y la capacidad de aprender; útiles ambos para perfeccionar el derecho internacional y crear la Carta Universal de los Derechos Humanos después de dos grandes guerras que devastaron Europa y otras partes del mundo. Desde 1945, cada día se está más cerca del respeto y aplicación del derecho internacional y de los derechos humanos en todos los países del orbe.

\section{BIBLIOGRAFÍA}

Alzogaray, Raúl, Historia de las células, Buenos Aires, Capital Intelectual Editorial, 2006.

Armstrong, David, The Mind-Body Problem: An Opinionated Introduction, Colorado, Westview Press, 1999.

Beurton, Peter, "Darwins Beitrag zum Genbegrif”, en Engels, EveMarie (ed.), Charles Darwin und seine Wirkung, Frankfurt am Main Suhrkamp Verlag, 2009.

BoAs, Franz, Textos de antropología, Madrid, Editorial Universitaria Ramón Areces, 2008. 
Esta revista forma parte del acervo de la Biblioteca Jurídica Virtual del Instituto de Investigaciones Jurídicas de la UNAM

Bochenski, M. Joseph, La filosofía actual, México, Fondo de Cultura Económica, 1965.

Boyer, Pascal, Und der Mensch schuf Gott, Stuttgart, Klett-Cotta Verlag, 2004.

BuRKERT, Walter, Kulte des altertums. Biologische Grundlage der Religion, München, C. H. Beck Verlag, 2009.

Campbell, Keith, Cuerpo y mente, México, UNAM, 1987.

Changeux, Jean-Pierre, El hombre de verdad, México, Fondo de Cultura Económica, 2005.

Darwin, Charles, The Descent of Man, and Selection in Relation to Sex, Georgia, Becker Press, vol. I y II, 1999.

- El origen del hombre y la selección natural en relación al sexo, traducción íntegra al español por la editorial Crítica: Barcelona, Editorial Crítica, 2009.

DAWKIns, Richard, The Greatest Show on Earth: The Evidence for Evolution, Nueva York, Free Press, 2008.

Dennetr, Daniel, Den Bann brechen. Religion als natürliches Phänomen, Frankfurt, Insel Verlag, 2008.

De WaAl, Frans, Der gute Affe, München, Hanser Verlag, 1997.

Engels, Eve-Mari \& DARWin, Charles: "Person, Theorie, Rezeption", en Engels, Eve-Marie (ed.), Charles Darwin und seine Wirkung, Frankfurt am Main, Suhrkamp Verlag, 2009.

Ehrencron, Phillipp, Antropologie des Rechts, München, Grin Verlag, 2008.

Ehrlich, Paul, Naturalezas humanas, México, Fondo de Cultura Económica, 2005.

GlASERSFELD, Ernst von, Radikaler Konstruktivismus: Ideen, Ergebnisse, Probleme, Frankfurt, Suhrkamp Verlag, 1997.

GöRnitz, Thomas y GöRnitz, Brigitte, Der Kreative Kosmos: Geist und Materie aus Information, Heidelberg, Spektrum akademischer Verlag, 2002.

HÄRING, Hermann, Das Böse in der Welt; Gottes Macht oder Ohnmacht?, Darmstadt, Primus Verlag, 1999. 
Esta revista forma parte del acervo de la Biblioteca Jurídica Virtual del Instituto de Investigaciones Jurídicas de la UNAM

HARRIS, Marvin, Introducción a la antropología general, Madrid, Alianza Editorial, 2002.

HAYEK, Friedrich, August von, Individualismus und wirtschaftliche Ordnung, Wien, Rentsch Verlag, 1952.

, Evolution, Wissen und spontane Ordnung, Die Anmassung von Wissen, Teil I, Mohr Verlag, Tübingen 1996.

HERMANni, Friedrich, "Naturalisierung der Ehtik", en WETZ-STEENBLock (eds.), Praktiche Philosophie, Stuttgart, Reclam, 2008.

Janich, Peter, "Naturwissenschaft vom Menschen versus Philosophie", en JANich, Peter (ed.), Naturalismus und Menschenbild, Hamburg, Meiner Verlag, 2008.

Junker, Thomas, "Die grosse Krise des Darwinismus", en Engels, Eve-Marie (ed.), Charles Darwin und seine Wirkung, Frankfurt am Main Suhrkamp Verlag, 2009.

KIM, Jaegwon, Philosophy of Mind, Colorado, Westview Press, 2010.

LAMPE, Ernst-Joachim, Rechtsantropologie, Berlín, Dunker \& Humblot Verlag, 1970.

Lazorthes, Guy, El cerebro y la mente, México, Conacyt-Ediciones Castell Mexicana, 1987.

MacLean, Paul, The Triune Brain Evolution. Role in Paleocerebral Functions, New York, Plenun Press, 1990.

MaInzer, Klaus (ed.), Komplexe Systeme und Nichtlineare Dynamik in Natur und Gesellschaft, Berlin-Heidelberg, Springer Verlag, 1999.

Mohr, Hans, Die Evolution von Altruismus, Heidelberg, Springer Spektrum, 2008.

— Evolutionäre Ethik, Heidelberg, Springer Spektrum, Heidelberg Akademie der Wissenschaft, 2014.

Popper, Karl, Eccles, John, Das Ich un sein Gerhirn, München, Piper Verlag, 1977.

RECKI, Birgit, "Kulturbejahung und Kulturverneinung", en WETZStEenblock (eds.), Praktiche Philosophie, Stuttgart, Reclam, 2008. 
REFLEXIONES FILOSÓFICAS SOBRE LA ANTROPOLOGÍA DEL DERECHO

WiTtGenSTEIN, Ludwig, Lecture on Ethics, Wiley, Blackwell University College 2014.

Wuketits, Franz, Darwin und der Darwinismus, München, C. H. Beck Verlag, 2005.

ZAK, Paul, "Die Neurobiologie des Vertrauens", en Das neue Genom, Frankfurt, Spektrum der Wissenschaft, 2006. 